\title{
The distribution and trends of fog and haze in the North China Plain over the past 30 years
}

\author{
G. Q. Fu' ${ }^{1,3}$, W. Y. Xu ${ }^{2,4}$, R. F. Yang ${ }^{1}$, J. B. $\mathbf{L i}^{5}$, and C. S. Zhao ${ }^{2}$ \\ ${ }^{1}$ Hebei Province Meteorological Service Centre, Shijiazhuang, Hebei, China \\ ${ }^{2}$ Department of Atmospheric and Oceanic Sciences, School of Physics, Peking University, Beijing, China \\ ${ }^{3}$ Key Laboratory for Meteorology and Ecological Environment of Hebei Province, Shijiazhuang, Hebei, China \\ ${ }^{4}$ Key Laboratory for Atmospheric Chemistry, Institute of Atmospheric Composition, Chinese Academy of Meteorological \\ Sciences, Beijing, China \\ ${ }^{5}$ Hebei Province Meteorological Observatory, Shijiazhuang, Hebei, China
}

Correspondence to: C. S. Zhao (zcs@pku.edu.cn)

Received: 29 April 2014 - Published in Atmos. Chem. Phys. Discuss.: 19 June 2014

Revised: 29 September 2014 - Accepted: 30 September 2014 - Published: 13 November 2014

\begin{abstract}
Frequent low visibility, haze and fog events were found in the North China Plain (NCP). Data throughout the $\mathrm{NCP}$ during the past 30 years were examined to determine the horizontal distribution and decadal trends of low visibility, haze and fog events. The impact of meteorological factors such as wind and relative humidity (RH) on those events was investigated. Results reveal distinct distributions of haze and fog days, due to their different formation mechanisms. Low visibility, haze and fog days all display increasing trends of before 1995, a steady stage during the period 1995-2003 and a drastically drop thereafter. All three events occurred most frequently during the heating season. Benefiting from emission control measures, haze and fog both show decreasing trends in winter during the past 3 decades, while summertime haze displays continuous increasing trends. The distribution of wind speed and wind direction as well as the topography within the NCP has determinative impacts on the distribution of haze and fog. Weakened south-easterly winds in the southern part of the NCP have resulted in high pollutant concentrations and frequent haze events along the foot of the Taihang Mountains. The orographically generated boundary layer wind convergence line in the central area of the southern NCP is responsible for the frequent fog events in this region. Wind speed has been decreasing throughout the entire southern NCP, resulting in more stable atmospheric conditions and weaker dispersion abilities, calling for harder efforts to control emissions to prevent haze events. Haze events are strongly influenced by the ambient RH. RH values asso-
\end{abstract}

ciated with haze days are evidently increasing, suggesting that an increasing fraction of haze events are caused by the hygroscopic growth of aerosols, rather than simply by high aerosol loadings.

\section{Introduction}

Low-visibility events caused by fog and severe haze events can be a heavy burden for air transport and on-road traffic. The severe aerosol pollution that has led to the visibility impairment is also highly damaging to human health.

In developed countries such as the US and the European countries, the employment of emission control measures for sulfur, nitrogen, hydrocarbon compounds and particulate matter has already resulted in significant declines in haziness and major improvements in visibility during the past 50 years (Schichtel et al., 2001; Doyle and Dorling, 2002; Molnár et al., 2008; Vautard et al., 2009). As a rapidly developing country, however, air pollution problems have been haunting China for the past few decades. Visibility has been deteriorating in southeast (Deng et al., 2012) and southwest China (Fu and $\mathrm{Wu}, 2011)$ during the past 50 years, with only a few places revealing slight increases in recent years. Six Chinese megacities have suffered from continuously decreasing visibilities in the past 30 years (Chang et al., 2009). Overall, visibilities on clear days decreased significantly during 
the period 1960-1990 over all of China; trends thereafter, however, have not been consistent (Wu et al., 2012).

The visibility trends were often attributed to the decrease in sulfur dioxide emissions or aerosol concentrations; however, no causality could be established so far. Both $\mathrm{SO}_{2}$ and aerosol pollution have been proved most severe in the North China Plain (NCP), due to the rapid economic growth and the high population density (Xu et al., 2011). As a result, low-visibility events frequently occur. Many in situ measurements and studies have already been performed to study the light scattering properties of aerosols and their impact on horizontal visibility under different relative humidity $(\mathrm{RH})$ in the NCP as part of the Haze in China (HaChi) Campaign (Chen et al., 2012; Ma et al., 2011). Results show that, under low RH, low-visibility events are mostly induced by the heavy aerosol loading, while under high $\mathrm{RH}$, the influence of aerosol hygroscopic growth becomes stronger and can lead to low-visibility events even under moderate aerosol pollution levels. However, only few studies have been performed to investigate the spatial distribution of low-visibility events and their overall trends during the past few decades in the NCP. Zhao et al. (2011) analysed the visibility trends in the NCP, suggesting declining visibilities before 1998 and increasing ones during the period 2006-2008, with stronger visibility deterioration trends in the summer season due to higher $\mathrm{RH}$ and lower wind speeds. Both haze and fog events could thus be responsible for low-visibility events; however, those were rarely differentiated in the study of visibility trends, which made it difficult to find the reason behind those visibility variations.

In this study, a detailed analysis on the decadal variation and spatial distribution of low visibility, fog and haze events in the most polluted southern part of the NCP will be performed, and the impact of wind and RH on those events will be revealed.

\section{Data and methodology}

The North China Plain (NCP) is surrounded to the north by the Yan Mountains, to the west by the Taihang Mountains and to the east by the Bohai Sea (Fig. 1). The western part of the NCP is affected by the warm and dry wind coming off the eastern Taihang Mountain slopes, which lead to increased surface stability. Under the influence of the Bohai Sea, the east coast of the NCP often experiences moderate to strong winds. The southern part of the NCP is rather flat and is an important water vapour transport passageway.

The locations of the 64 meteorological observation sites selected for this study are displayed in Fig. 1, with the names of the sites given in Fig. 2a. All sites are located in the southern part of the NCP, where the air pollution is most severe. The visibility, RH, wind speed and weather phenomenon observed at 14:00 local time (LT) during the period 1981-2010

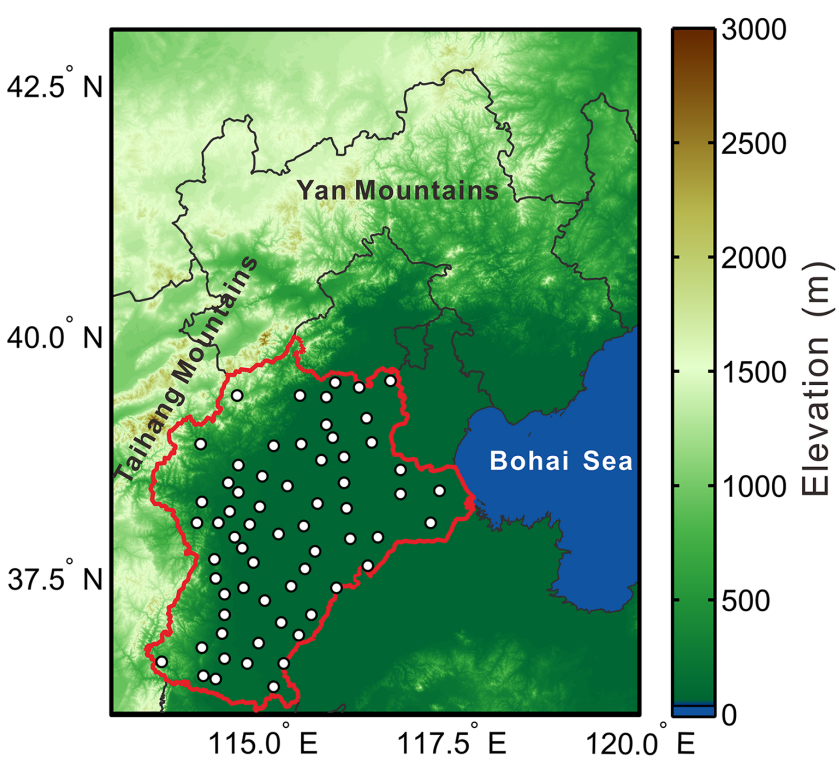

Figure 1. The location of the measurement sites (circle), the area of study (red line) and the regional topography by Danielson and Gesch (2011) (colour).

were used to analyse the long-term temporal and spatial variation of low visibility, haze and fog events.

Both haze and fog can lead to low-visibility events. The formations of haze and fog are two distinctly different processes. Therefore, it is necessary to differentiate between those two events when analysing low-visibility trends, distributions and variations. In this work, low-visibility events were defined as days with visibility at 14:00 LT below $10 \mathrm{~km}$. Those low-visibility events that were not associated with fog, precipitation, dust storms, smoke, snow storms etc. were defined as haze events. Fog events mostly occur during early morning, rarely lasting until 14:00 LT. Therefore, a day was defined as a foggy day if the occurrence of fog was recorded at any time during the day.

For each station the occurrences of low-visibility days, hazy days and foggy days during the period 1981-2010 were counted to analyse the spatial distribution of those three types of events. OMI Level $3 \quad \mathrm{SO}_{2} \quad$ (OMSO2 Readme file v1.1.1, http://so2.gsfc.nasa.gov/Documentation/ OMSO2ReleaseDetails_v111_0303.htm) planetary boundary layer column concentrations during 2005-2012 were used to show the correlation between the distribution of $\mathrm{SO}_{2}$ and the occurrence of haze days.

The spatial average annual and 10-year moving average frequency of occurrence during the period 1981-2010 were used to analyse the trend of the three types of events over those 30 years. The trends are then compared to the $\mathrm{SO}_{2}$ emission trends inferred from the China statistical yearbooks (National Bureau of Statistics of China, 1995-2010). The spatial averages of monthly frequency of occurrence during 

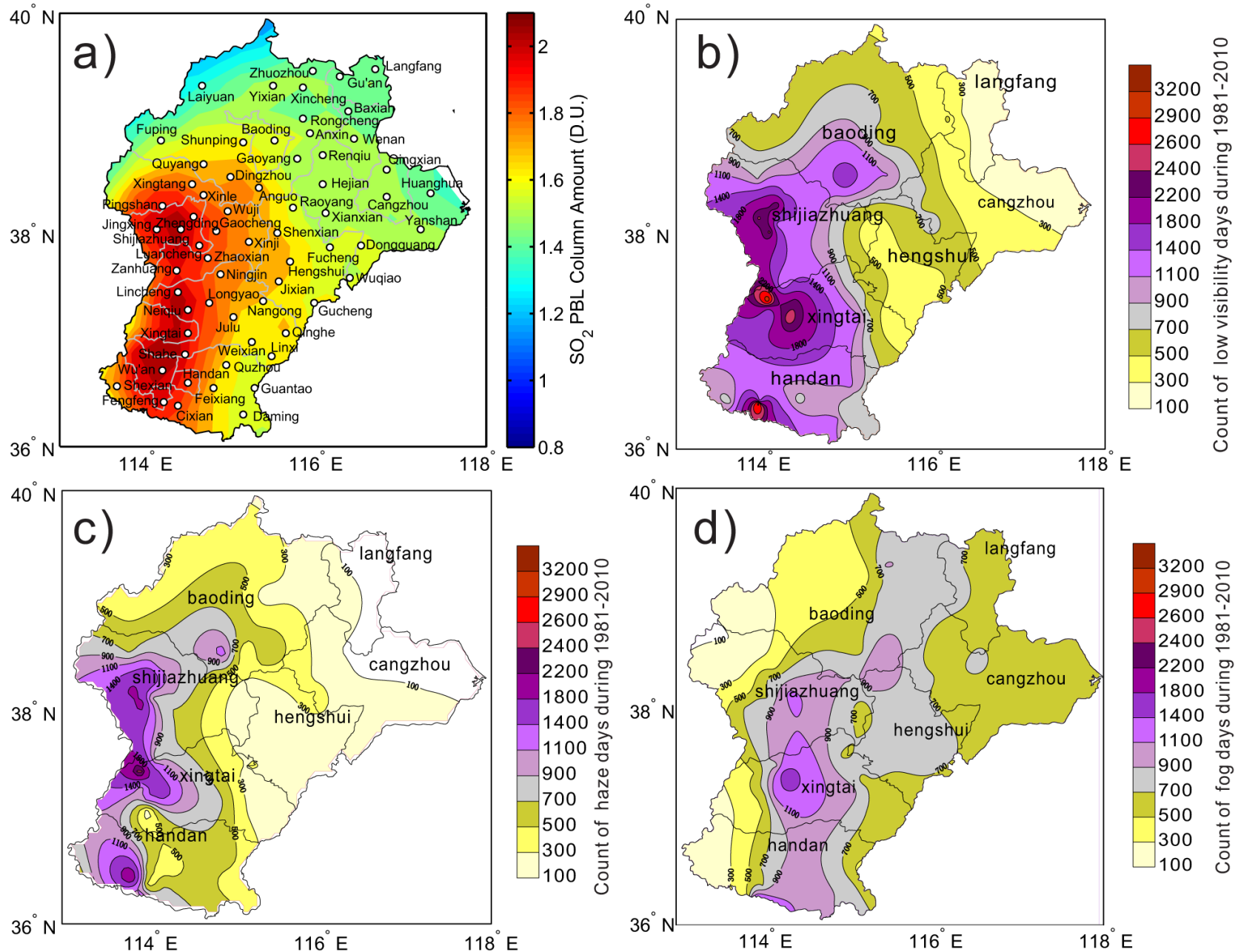

Figure 2. (a) Average OMI SO2 PBL column amount during the period 2005-2012 with the location of the 64 stations and the number of (b) low visibility, (c) haze and (d) fog days during the period 1981-2010 in the southern NCP.

the period 1981-2010 were applied to examine the long-term trend of those three types of events in different seasons.

The average distribution and the linear trend of wind speeds during the period 1981-2010 were respectively calculated to reveal their impact on the distribution and trend of the frequency of occurrence of the three types of events. NCEP final analysis meteorology data during 58 fog days in between January 2009 and February 2010 were used to reveal the characteristic wind field that has led to fog events in the southern NCP. Surface automatic weather station wind data during May-December 2009 were used as supplements to analyse the distribution of the wind field in the entire NCP and how it impacts haze formation.

The average distribution of the number of days with $14 \mathrm{~h} \mathrm{RH}>70 \%$ and the number of haze days with $14 \mathrm{~h}$ $\mathrm{RH}>70 \%$ was calculated to show its relation to the distribution of low visibility, haze and fog events. To further study the influence of RH on haze events, the decadal variation of the ratio of the annual average haze related $\mathrm{RH}$ to the total average RH was compared against the decadal variation in annual haze days. The seasonal-decadal trend of the frequency of occurrence of haze-related $\mathrm{RH}$ values falling in the range of $\mathrm{RH}<50 \%, 50 \%<\mathrm{RH}<60 \%$, $60 \%<\mathrm{RH}<70 \%, \mathrm{RH}>70 \%$ was analysed to show the impact RH has on haze in different seasons.

\section{Results and discussions}

\subsection{The spatial distribution of low visibility, haze and fog}

Low visibility, haze and fog events are formed through different mechanisms; hence their occurrences are determined by different parameters. This may lead to distinct spatial distributions of the frequency of occurrence. The spatial distributions of the occurrences of low visibility, haze and fog 
Table 1. The number (percentage) of stations under various count ranges of low visibility, haze and fog days during 1981-2010.

\begin{tabular}{lrrrrrr}
\hline \multirow{2}{*}{ Stations } & $\geq 3000$ & $2000-2999$ & $1000-1999$ & $500-999$ & $100-499$ & $<100$ \\
\hline Low visibility & $2(3 \%)$ & $6(9 \%)$ & $22(34 \%)$ & $23(36 \%)$ & $11(17 \%)$ & $0(0 \%)$ \\
Haze & $0(0 \%)$ & $2(3 \%)$ & $12(19 \%)$ & $15(23 \%)$ & $30(47 \%)$ & $5(8 \%)$ \\
Fog & $0(0 \%)$ & $0(0 \%)$ & $8(13 \%)$ & $47(73 \%)$ & $9(14 \%)$ & $0(0 \%)$ \\
\hline
\end{tabular}

days during the period 1981-2010 in the southern NCP are depicted in Fig. 2b-d.

Haze events are caused by either high aerosol loadings or the strong hygroscopic growth of aerosols. $\mathrm{SO}_{2}$ is the main precursor of sulfate aerosols, which are highly hygroscopic and exist in abundance in the NCP (Liu et al., 2014). The average $\mathrm{SO}_{2}$ planetary boundary layer (PBL) column amount during the period 2005-2012 is depicted in Fig. 2a. High $\mathrm{SO}_{2}$ column concentrations are found on the western border, which is caused on the one hand by the large amount of $\mathrm{SO}_{2}$ emissions in this region and on the other hand by the special topography which leads to poor dispersion conditions. The high $\mathrm{SO}_{2}$ concentrations have led to large loadings of highly hygroscopic sulfate aerosol, which can easily lead to haze events in this region. Figure $2 \mathrm{c}$ displays the distribution frequency of haze days, which shows a very similar distribution to that of $\mathrm{SO}_{2}$ column concentration. Haze also most frequently occurs on the western border of the NCP, along the eastern slope of the Taihang Mountains.

The distribution of fog days is distinctly different than that of haze days (Fig. 2d). Fog events most commonly occur along the centre line of the plain region, parallel to the southwest-northeast ridge of the Taihang Mountain. This suggests that the formations of haze and fog are controlled by different physical processes. While the formation of haze mainly depends on the local aerosol pollution level, the formation of fog is not limited to the presence of cloud condensation nucleus under the regional pollution state of the NCP. The special topography and meteorology in the NCP could be responsible for the spatial distribution of fog event occurrences, which will be further discussed in Sect. 3.3.2.

Low-visibility events can be caused by both haze and fog. The area with the most low-visibility days covers both the area with the most haze and fog days. Low visibility mainly happens in the western part of the region, which is similar to the distribution of haze days. High centres were found around the three major cities Shijiazhuang, Xingtai and Handan. This indicates that low-visibility events in the NCP are mostly caused by haze, rather than by fog.

Due to the distinct spatial distribution of low visibility, haze and fog days, the spatial coverage of their influence is also different. Table 1 lists the number (percentage) of stations within various count ranges of low visibility, haze and fog days during the period 1981-2010. In the southern NCP, 34 and $36 \%$ of the stations have respectively observed
500-999 and 1000-1999 low-visibility days, while another $12 \%$ of the stations have gone through more than 2000 lowvisibility days and $17 \%$ rather clean stations have only had 100-499 low-visibility days. Although haze events can be very frequent, their impact is largely constrained within the limited area in the southwest; $22 \%$ of the sites have experienced more than 1000 haze days during the past 30 years, while $55 \%$ of the sites have had fewer than 500 haze days. For fog events, however, $73 \%$ of the sites have experienced 500-999 fog days during the past 30 years, suggesting that a large area is under a similar influence of fog events.

In all, low visibility, haze and fog days are distinctly distributed in the NCP, because their formations are controlled by different mechanisms. The spatial distribution of haze days is determined by the distribution of pollutant emissions and by the topography of the NCP, thus only influencing a small area near the edge of the mountains. The distribution of fog days is mainly determined by the topography and meteorology, affecting a large area parallel to the mountains. Low visibility is mostly induced by haze events, thus showing a similar distribution to that of haze days.

\subsection{The trends of low visibility, haze and fog during the period 1981-2010}

The temporal trends of low visibility, haze and fog are influenced by the variation of many factors such as pollutant emissions, aerosol compositions and meteorological conditions, etc. During the past 30 years, the NCP has undergone rapid economic developments accompanied by growing energy consumptions. In the past decade, policies were made to reduce pollutant emissions in the NCP in hope of improving the air quality there. In this section, the decadal trends of low visibility, haze and fog days will be examined to show the combined effect of various influencing factors.

\subsubsection{The decadal trends of low visibility, haze and fog}

The decadal variations of the annual and the 10-year moving average of the occurrence of low visibility, haze and fog days during the period 1981-2010 are displayed in Fig. 3b. Before 1995, due to the rapid economic development, increasing energy consumption led to increasing numbers of haze and fog days, which resulted in more frequent low-visibility events. During the period 1995-2003, with the development and employment of waste gas processing techniques, occurrences of 

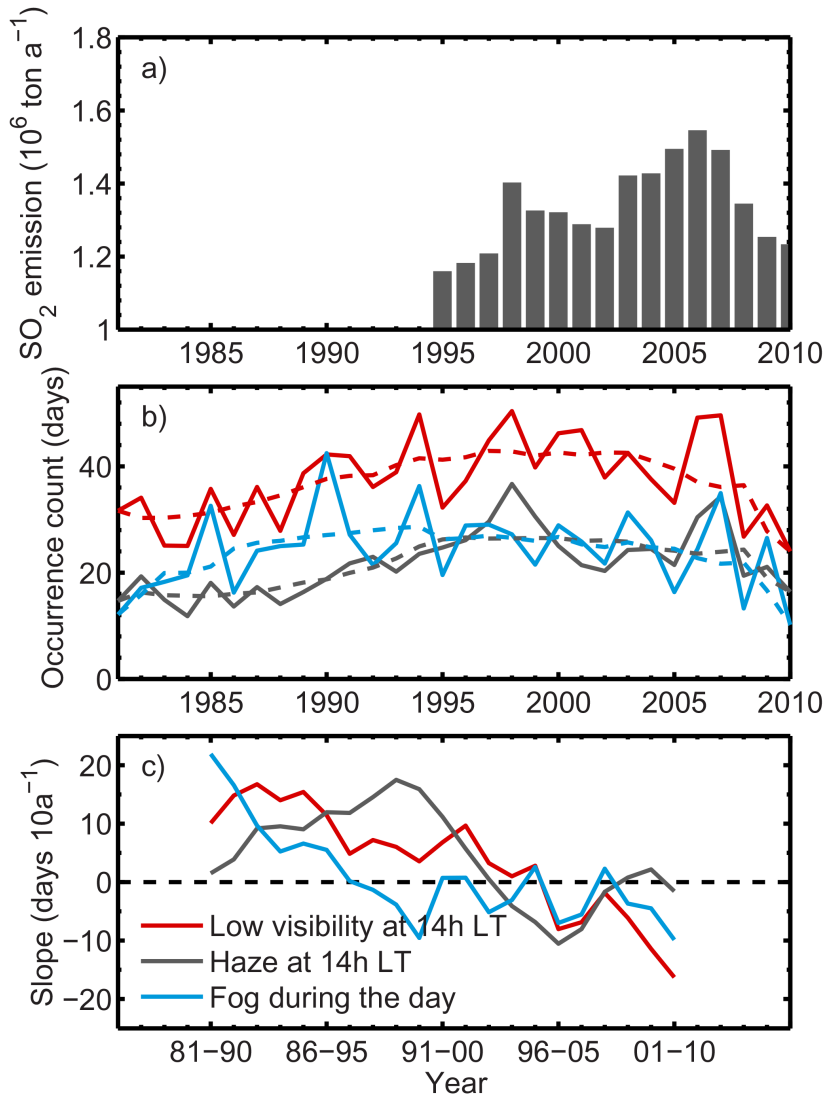

Figure 3. (a) The annual $\mathrm{SO}_{2}$ emissions in Hebei Province inferred from the China statistical yearbooks (National Bureau of Statistics of China, 1995-2010); (b) the annual (solid lines) and the 10-year moving average (dashed lines) occurrence of low visibility, haze and fog days among the 64 stations during the period 1981-2010; (b) the slope of the linear fits to the 10-year moving averages of low visibility, haze and fog days among the 64 stations during the period 1981-2010.

low visibility, haze and fog days entered a steady stage. After 2003, in preparation for the 2008 Beijing Olympic Games, under the influence of emission control policies, the number of low visibility, haze and fog days drastically dropped. The trend of low visibility and haze days agrees well with that of the $\mathrm{SO}_{2}$ emissions (Fig. 3a), suggesting that the control in emissions during the last decade effectively led to increased visibility and the decline in the number of hazy days.

The slopes of the linear fits to the 10-year moving averages of low visibility, haze and fog occurrence days during the period 1981-2010 are shown Fig. 3c. The maximum increasing slope for haze events can be found between 1989 and 1998 , reaching 17 days 10 year $^{-1}$. After the period of 1994-2003, haze events generally declined, reaching a maximum decreasing slope of 11 days 10 year $^{-1}$ during the period 1996-2005. After the period of 1987-1996, fog occurrences show a variable but generally decreasing trend. Major decreases occurred during the periods of 1990-1999 and
2001-2010, with slopes of 10 days 10 year $^{-1}$. The number of low-visibility days increased before the period of 1996-2005, with a maximum slope of 17 days 10 year $^{-1}$ during the period 1983-1992. Afterwards, low-visibility events were found to be less frequent; the maximum decreasing slope was found during the period 2001-2010, reaching 16 days 10 year $^{-1}$.

Generally, the frequencies of occurrence of low visibility, haze and fog in the NCP have all increased during the period 1980-1990. Due to the effect of $\mathrm{SO}_{2}$ emission reduction during the past few years, the occurrences of low visibility, haze and fog have all decreased back to a similar level as in 1980.

\subsubsection{The seasonal-decadal trends of low visibility, haze and fog}

Low visibility, haze and fog are strongly influenced by meteorological conditions, which in the NCP vary distinctly with season. This may cause different decadal variation in different seasons. Figure 4 shows the seasonal-decadal trends of the frequency of occurrence of low visibility, haze and fog during the period 1981-2010.

During the past 30 years, haze events were most common during the heating season (Nov-Mar) and least common during the end of spring and early autumn (Fig. 4d). After 1990, haze events started to appear not only during the heating season but also during summertime (Fig. 4b2). From the 10-year moving average frequency of occurrence of haze in spring, summer, autumn and winter (Fig. 4b1), it can be seen that summertime haze occurrence frequency has been continuously increasing in the past 3 decades, while that in wintertime has been declining since 1995 . In the past, residential and commercial heating during winter has led to high emissions of soot, which were responsible for the degradation of visibility. With the development of central heating and waste gas processing techniques, emissions from heating processes have been gradually declining, leading to fewer haze events during winter. However, atmospheric pollution has become more complex during recent years. During summer, the atmosphere becomes highly oxidative, and aerosol pollution coexists with high concentrations of $\mathrm{O}_{3}$ and volatile organic compounds (VOCs) (Ran et al., 2011), which contribute to the fast aging and secondary formation of aerosols. Aged aerosols are more hygroscopic and can easily lead to haze events under suitable RH conditions (Chen et al., 2012). The increased use of air conditioning during summertime has resulted in increasing energy consumption trends (Zhang, 2004), which could also lead to increased aerosol loading and reduced visibility during summer.

Fog events appear most frequently during winter and least frequently during spring until early summer. The frequency of occurrence of fog during the past 30 years shows no significant trend in spring and summer, but shows a declining trend during winter after 1990 (Fig. 4c1). 

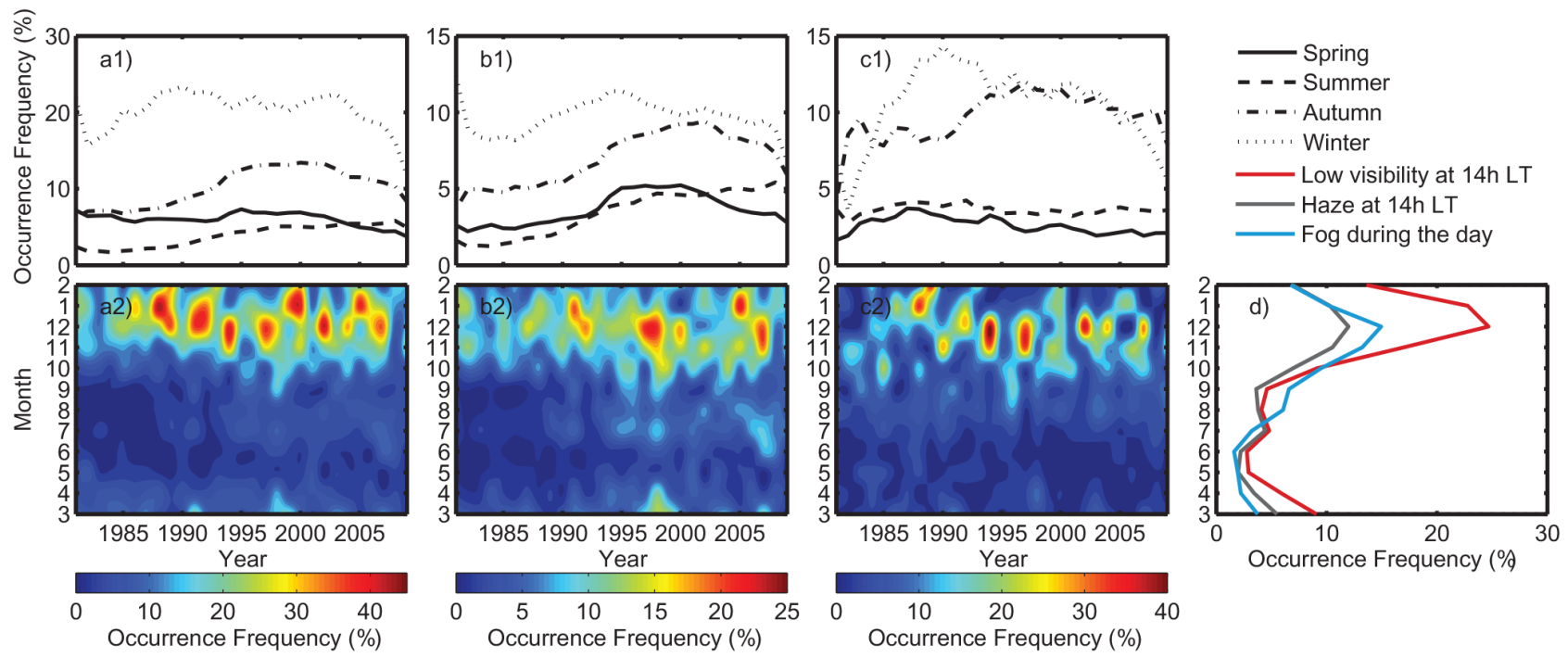

Figure 4. (1) The trend of the 10-year moving average frequency of occurrence of (a) low-visibility events at 14:00 LT, (b) haze events at 14:00 LT and (c) fog events during the day among the 64 stations during spring (MAM), summer (JJA), autumn (SON) and winter (DJF). (2) The seasonal-annual variation of the average frequency of occurrence of (a) low-visibility events at 14:00 LT, (b) haze events at 14:00 LT and (c) fog events during the day among the 64 stations and (d) the seasonal variation of the average frequency of occurrence of low-visibility events at 14:00 LT, haze events at 14:00 LT and fog events among the 64 stations during 1981-2010.

Low-visibility events are caused by both haze and fog. Their combined effect has resulted in high frequency of occurrence of low visibility during winter and lower ones during spring and summer (Fig. 4a1). Low-visibility events during summertime have been continuously increasing in the past 3 decades, while those during spring, autumn and winter have been decreasing since 2000 .

In all, wintertime low visibility, haze and fog days have been declining, while summertime low visibility and haze days have been increasing due to the variation in aerosol composition and the summertime high RH that favours the hygroscopic growth of particles. Additionally, the increased energy consumption due to air conditioning might also lead to increased summertime aerosol loadings and decreased visibilities.

\subsection{The impact of wind on low visibility, haze and fog}

\subsubsection{The impact of wind on haze}

Wind direction can influence the transport of pollutants, thus determining the spatial distribution of visibility degrading pollutants. Wind speed greatly influences the atmospheric stability and the atmospheric dispersion capability. Low wind speeds suggest that the atmosphere is rather stable and the dispersion of local emissions is limited.

Figure 5a shows the spatial distribution of the average $14 \mathrm{~h}$ (LT) surface wind direction during May-December 2009 in the entire NCP. The Yan and Taihang mountains are governed by northwest winds, while the plain area is dominated by winds from the south. Along the south-western edge of the Taihang Mountains, the winds all come from the southeastern direction, which can transport the emitted pollutants from the eastern part of the plain area to the western part. The weak north-western winds in the mountains block pollutant transport, leading to the accumulation of heavy loadings of aerosol and its precursors along the foot of the Taihang Mountains. This explains why haze events are most common in this region.

Figure 6a displays the distribution of the average $14 \mathrm{~h}$ (LT) wind speed during the period 1981-2010. Average wind speeds at $14 \mathrm{~h}$ (LT) decrease from the southeast to the northwest. Lowest values are found in the northwest corner, decreasing below $3 \mathrm{~m} \mathrm{~s}^{-1}$, while similar values were also detected in Xingtai and Handan, two heavily polluted cities in the southern corner. Average wind speeds near the coast (in the vicinity of Cangzhou) and in the southeast corner are large, reaching over $5 \mathrm{~m} \mathrm{~s}^{-1}$. The low wind speeds are caused primarily by the Taihang Mountains, which slow down westerly winds before they reach the plain region. As can be seen from Fig. 5, the Taihang Mountains are higher in the north and lower in the south, which explains why wind speeds are lowest in the northwest corner. Another factor influencing the surface wind speed is the surface roughness. Large cities with densely distributed high buildings will add to the surface roughness and slow down near surface winds.

Although dispersion abilities are weakest in the northwest corner, due to relatively lower pollutant emissions in the mountain areas, low visibility and haze events are rare on the northwestern edge. However, the area near Baoding, where the pollution level is slightly higher than in the mountain 

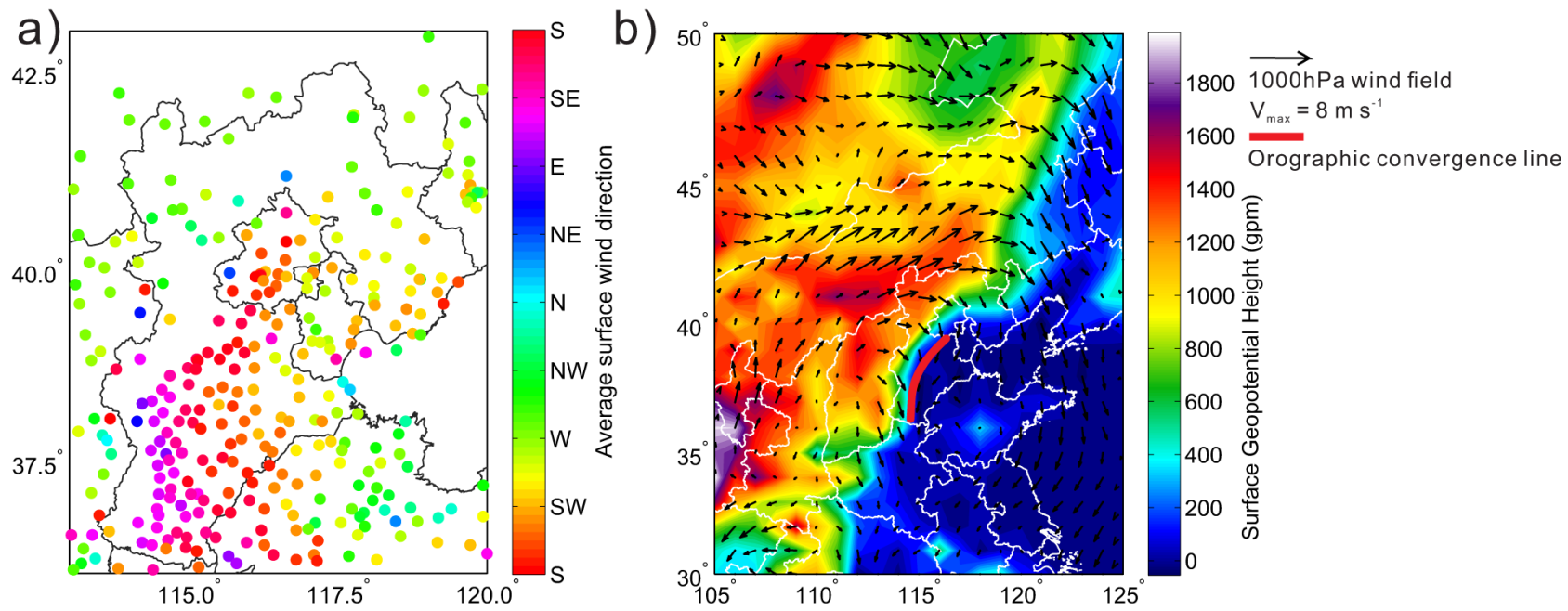

Figure 5. (a) Averaged $14 \mathrm{~h}$ surface wind direction during May-December 2009 given by 307 AWS stations. (b) The orographic geopotential height above sea level (shading), the average $8 \mathrm{~h} 1000 \mathrm{hPa}$ NCEP final analysis wind field (black arrows) and the orographically generated wind convergence line (red line) of 58 fog days during January 2009-February 2010.
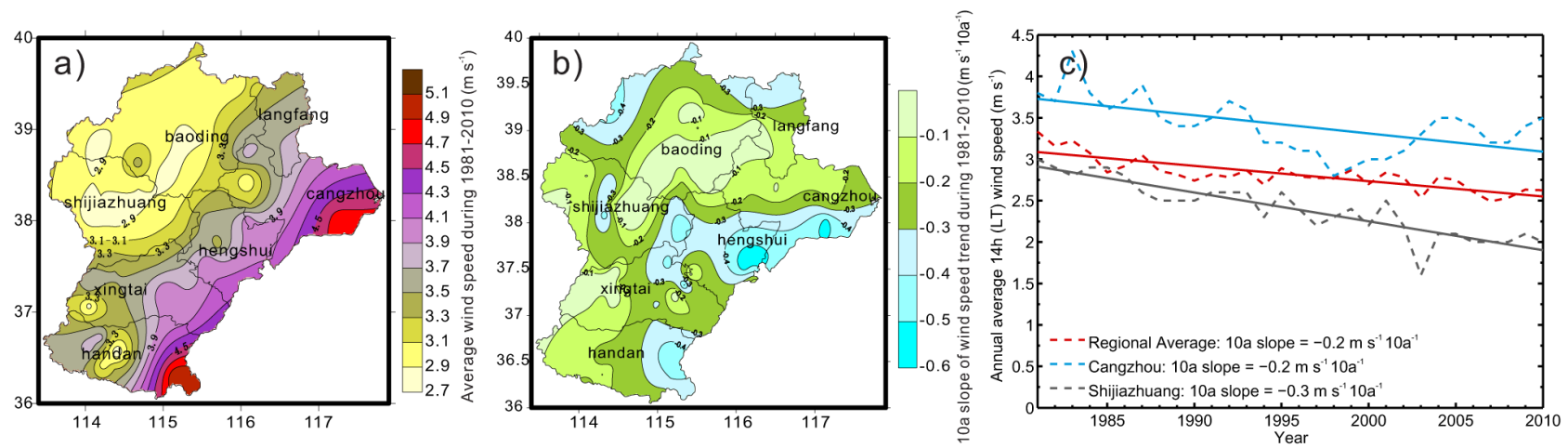

Figure 6. (a) Distribution of the average $14 \mathrm{~h}$ (LT) wind speed during 1981-2010 in the southern NCP; (b) distribution of the linear slope of the annual wind speed during 1981-2010 in the southern NCP; (c) variation (dashed lines) and linear trend (solid lines) of the regional average $14 \mathrm{~h}$ (LT) wind speed and that of Cangzhou and Shijiazhuang during 1981-2010.

areas and distinctively lower than over the polluted region in the southwest, is heavily affected by the low wind speeds, showing frequently occurring low visibility and haze events. The southwestern edge of the southern NCP region suffers from high pollutant emissions and is subject to conditions that lead to relatively weak dispersion. The low average wind speed centres in Shijiazhuang, Xingtai and Handan (Fig. 7a) conform to the high haze day count centres (Fig. 2c).

Figure $6 \mathrm{~b}$ shows how the linear slope of the annual wind speed during 1981-2010 is distributed in the southern NCP. Over the entire region, wind speeds have been decreasing in the past 30 years. Large decreasing slopes were found in those regions with high average wind speeds, but also in parts of the northeast corner and in Shijiazhuang, which is the capital of Hebei Province. The regional average 10-year decreasing slope reaches $0.2 \mathrm{~m} \mathrm{~s}^{-1} 10$ year $^{-1}$, while that in Shijiazhuang reaches over $0.2 \mathrm{~m} \mathrm{~s}^{-1} 10$ year $^{-1}$ (Fig. 6c). The decrease in wind speed suggests that the atmosphere has become more stable and dispersion capabilities have weakened throughout the entire region, which calls for even more extreme efforts to control emissions in order to prevent haze events.

\subsubsection{The impact of wind on fog}

The formation of fog needs a supersaturated water vapour environment, which requires favourable meteorological conditions. Figure $5 \mathrm{~b}$ shows the average 08:00 (LT) $1000 \mathrm{hPa}$ wind field during 58 fog days that occurred between January 2009 and February 2010, on which more than 10 stations reported the occurrence of fog. Due to the topography of the NCP, an orographically generated, boundary layer wind convergence line going from southwest to the northeast is formed as indicated by the red line in Fig. 5b. The convergence line is 

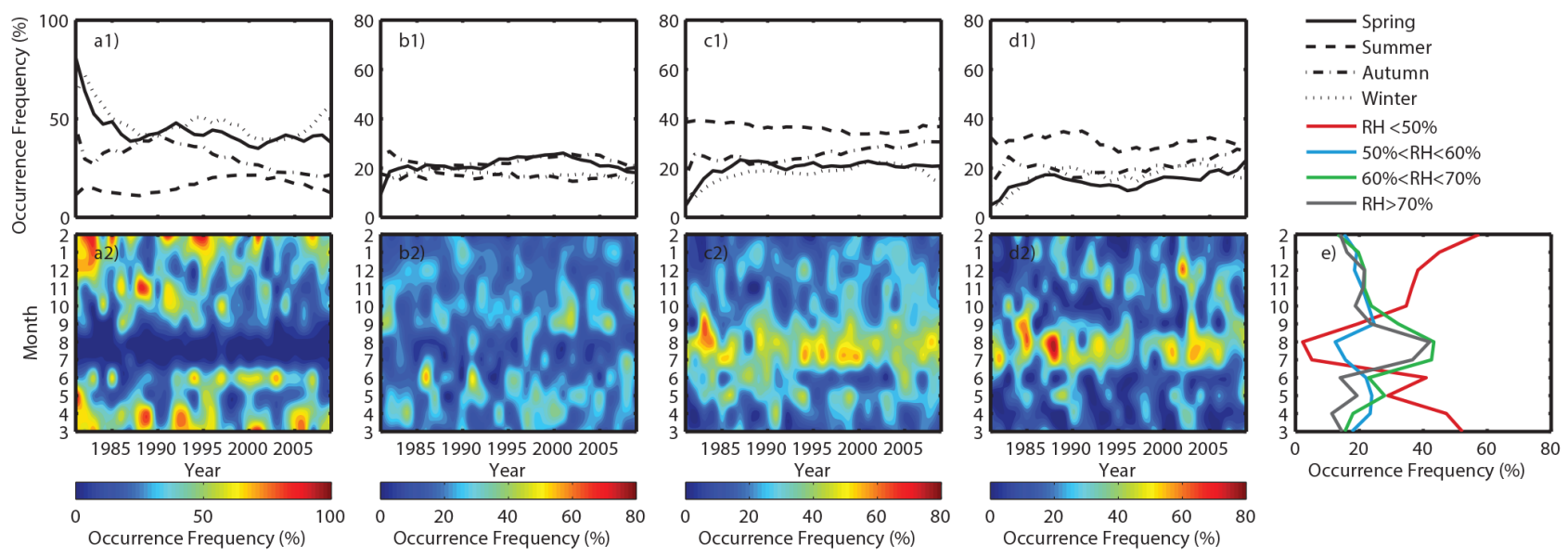

Figure 7. (1) The decadal trend of the 10-year moving average frequency of occurrence of 14h (LT) haze event RH in the range of (a) $\mathrm{RH}<50 \%$, (b) $50 \%<\mathrm{RH}<60 \%$, (c) $60 \%<\mathrm{RH}<70 \%$ and (d) $\mathrm{RH}>70 \%$ during spring (MAM), summer (JJA), autumn (SON) and winter (DJF). (2) The seasonal-decadal variation of the frequency of occurrence of $14 \mathrm{~h}$ (LT) haze event RH in the range of (a) RH $<50 \%$, (b) $50 \%<\mathrm{RH}<60 \%$, (c) $60 \%<\mathrm{RH}<70 \%$ and (d) $70 \%<\mathrm{RH}<80 \%$ and (e) the seasonal variation of the average frequency of occurrence of $14 \mathrm{~h}$ (LT) haze event $\mathrm{RH}$ in the range of (a) $\mathrm{RH}<50 \%$, (b) $50 \%<\mathrm{RH}<60 \%$, (c) $60 \%<\mathrm{RH}<70 \%$ and (d) $\mathrm{RH}>70 \%$ during the period 1981-2010.

also parallel to the ridge of the Taihang Mountains, coinciding with the zone with the most frequent fog events (Fig. 2d). Fog events usually occur during the night, when the mountain areas cool off faster than the plain area, forming a temperature gradient. To the west of the convergence line, near surface winds are dominated by cold north-westerly mountain winds, while to the east of the convergence line, surface winds are north-easterly or south-easterly. With the northeasterly winds comes the warm humid air from the Bohai Sea, while the south-easterly path is the most typical water vapour transport passage way for the entire NCP region. The convergence zone will hence favour the accumulation and convergence of water vapour, and lead to the formation of fog in this area.

\subsection{The impact of RH on low visibility, haze and fog}

The ambient RH can influence the visibility by affecting the hygroscopic growth and scattering abilities of atmospheric aerosols. Chen et al. (2012) suggest that, under RH $<80 \%$, visibility is highly dependent on dry aerosol volume concentrations. The hygroscopic growth of aerosols in this RH range only becomes important for visibility impairment if the aerosol loading is high, while for RH greater than $80 \%$ the hygroscopic growth of aerosols can greatly affect visibility, even under average aerosol pollution levels.

The distribution of the number of days with $14 \mathrm{~h}$ (LT) $\mathrm{RH}>70 \%$ and the number of haze days with $14 \mathrm{~h}$ (LT) $\mathrm{RH}>70 \%$ are depicted in Fig. 8. High RH days most frequently occur in the southeast, where there is a water vapour transport passageway, and along the convergence line, which was observed to be favourable for the formation of fog events in Sect. 3.3.2. The distribution of the number of haze days with $14 \mathrm{~h}$ (LT) $\mathrm{RH}>70 \%$ (Fig. 8b) is similar to that of the number of all days with $14 \mathrm{~h}$ (LT) RH $>70 \%$ (Fig. 8a), only with significantly smaller numbers to the east of Shijiazhuang, because haze is not as severe in that region. Compared with the distribution of the total number of low visibility and haze days (Fig. 2b-c), it can be noted that the frequent low-visibility events along the southern edge of the Taihang mountain were caused primarily by the heavy aerosol pollution and not by haze events associated with high RH. The low-visibility events in the vicinity of Shijiazhuang, however, were not only caused by severe pollution but were also associated with high RH events, indicating that the hygroscopic growth of aerosols plays an important role in the visibility impairment in this region. Although aerosol pollution is not as severe in the south-eastern part of our area of study, a large fraction of haze days are associated with high RH events, suggesting that the high RH in this region is able to impair visibility even if the aerosol concentration is not very high. The hygroscopic growth induced light scattering of aerosols plays a dominant role in the degradation of visibility in this region.

The $14 \mathrm{~h}$ (LT) RH values that were accompanied by haze events (haze event RH) were sorted out and its frequency of occurrence in the range of $\mathrm{RH}<50 \%, 50 \%<\mathrm{RH}<60 \%$, $60 \%<\mathrm{RH}<70 \%$ and $\mathrm{RH}>70 \%$ was calculated for each station in each month during the period 1981-2010. Figure $7 \mathrm{a} 2-\mathrm{d} 2$ show the regional average seasonal-decadal variation of the frequency of occurrence of haze event RHs. It can be noted that haze events mostly occur under RH $>60 \%$ during summer and early autumn, while during late autumn, winter and spring, haze events mostly occur under $\mathrm{RH}<60 \%$. This suggests that haze events during the warm 

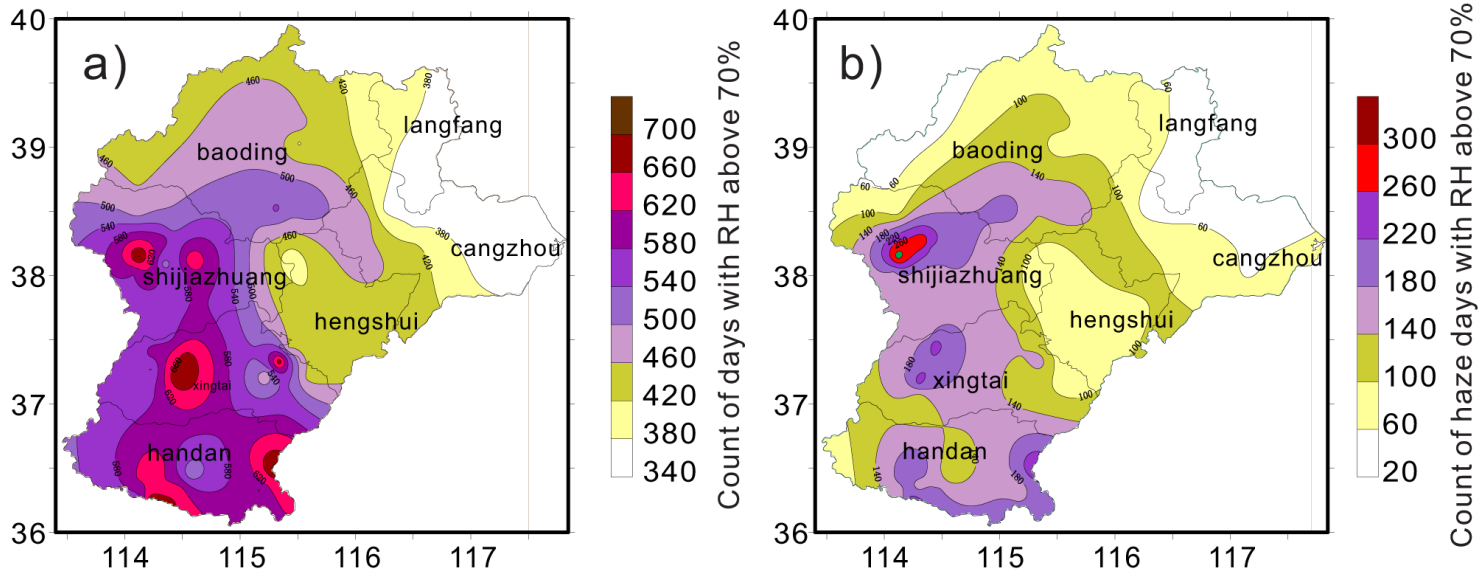

Figure 8. The distribution of (a) the number of days with $14 \mathrm{~h}$ (LT) RH above $70 \%$ and (b) the number of haze days with $14 \mathrm{~h}$ (LT) RH above $70 \%$ during 1981-2010 in the southern NCP.

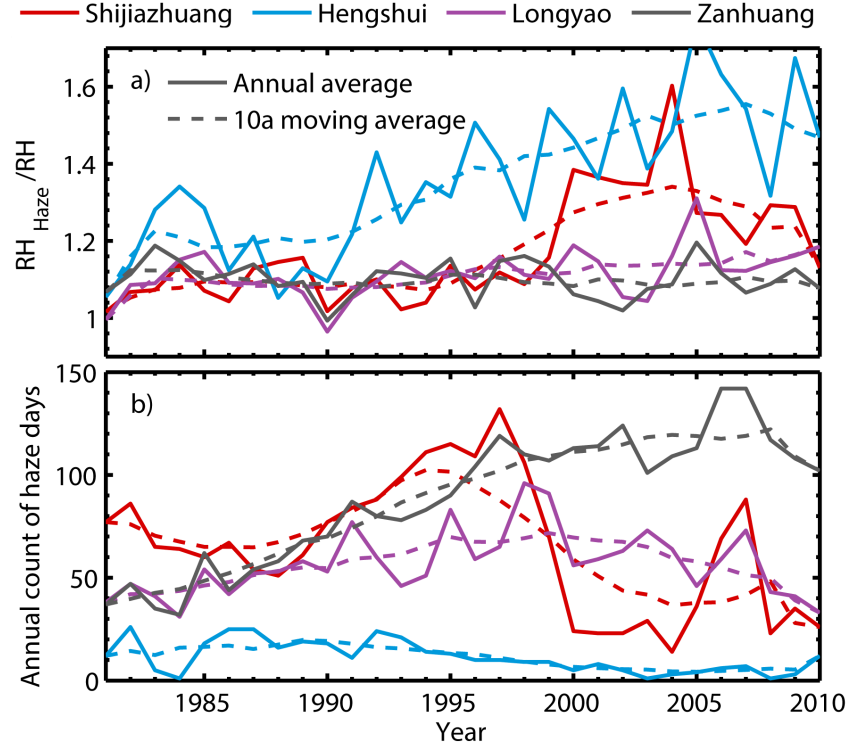

Figure 9. (a) The decadal variation of the haze event associated RH divided by the average RH and (b) the annual number of haze days during the period 1981-2010 at Shijiazhuang, Hengshui, Longyao and Zanhuang.

season are caused both by high aerosol loadings and their hygroscopic growth, while those in the cold seasons are mostly induced by high aerosol loadings.

The frequency of occurrence of haze events under low $\mathrm{RH}(\mathrm{RH}<50 \%)$ in autumn, winter and spring has decreased over the past 30 years, with a slight rebound in the winter time data at the end of the last decade. This indicates that aerosol loadings during winter have declined, which could be the result of effective emission control measures during heating seasons. The frequency of occurrence of haze events under higher $\mathrm{RH}(\mathrm{RH}>60 \%)$ in autumn, winter and spring show increasing trends during the past 30 years. A possible cause could be the fact that atmospheric pollution has become more complicated over the years, leading to a higher fraction of secondary aerosols, which are more hygroscopic and are more likely to impair visibility through hygroscopic growth processes.

To further study if this phenomenon exists throughout the entire region, the decadal variation of haze event $\mathrm{RH}$, annual average RH and annual haze days at four representative stations were analysed as is depicted in Fig. 9. The RH associated with haze events is typically higher than the average $\mathrm{RH}$ values. Zanhuang station shows continuously increasing number of haze days throughout the past 30 years, while Hengshui displays a continuous decline throughout the past 20 years (Fig. 9b). Shijiazhuang and Longyao have both undergone an increase before 2000 and a decrease thereafter. Significant increasing trends can be found in the ratio of haze event RH and average RH at all four stations (Fig. 9a). This means that a higher fraction of the haze events are now caused by the hygroscopic growth of aerosols. The reduction in primary aerosol emissions further amplifies this effect.

\section{Summary}

In this study, the spatial distribution and decadal variation of low visibility, fog and haze events in the most polluted southern part of the NCP during the past 30 years were analysed and the impact of wind and $\mathrm{RH}$ on those events was investigated.

Haze and fog are distinctly distributed, which was determined by the topography of the NCP and the distribution of wind speed and wind direction. Haze occurs mostly along the south-western edge of the plain region, while fog mostly occurs within the central band area parallel to the ridge of the Taihang Mountains. 
Annual low visibility, haze and fog days have shown increasing trends before 1995, have entered a steady stage during the period 1995-2003 and have drastically dropped thereafter during the preparation stage for the Beijing Olympic Games in 2008. Low visibility, haze and fog events all occurred most frequently during the heating season in the past 3 decades. Wintertime haze and fog both show decreasing trends, as a benefit of the improvements in central heating and desulfurization techniques. Summertime haze, however, displayed continuously increasing trends during the period 1981-2010.

Both the distribution of the wind field and the decadal variation of wind speeds have great impacts on the occurrence of low visibility, haze and fog events. South-easterly winds in the southern part of the NCP which are blocked by the weak north-western winds in the Taihang Mountains has resulted in high pollutant concentrations along the foot of the mountain, which has led to frequent haze events. The convergence zone parallel to the ridge of the Taihang Mountains in the central area of the southern NCP was responsible for the frequent fog events in this region. Wind speed has been decreasing throughout the entire southern NCP, resulting in more stable atmospheric conditions and thus stronger inversions and reduced dispersion capability, which calls for even increased efforts to control emissions in order to prevent haze events.

Haze and low-visibility events were strongly influenced by the ambient RH. The frequent high RH events near Shijiazhuang and in the south-eastern part of the region favours the hygroscopic growth of aerosols and plays a dominant role in the visibility impairment in those areas. Under RH below $60 \%$, haze events mostly occurred during the heating seasons, while for RH above $60 \%$, haze events were more likely to happen during summertime. Although annual RH values displayed no significant trends within the past 30 years, those $\mathrm{RH}$ values associated with haze days were evidently increasing, suggesting that an increasing fraction of haze events are caused by the hygroscopic growth of aerosols, rather than simply by high aerosol loadings.

Acknowledgements. This work is supported by the National 973 project of China (2011CB403402), the National Natural Science Foundation of China under grant no. 41375134, the Beijing Natural Science Foundation (8131003), the Beijing Municipal Science and Technology Plan Project no. Z131100006113013.

Edited by: D. Covert

\section{References}

Chang, D., Song, Y., and Liu, B.: Visibility trends in six megacities in China 1973-2007, Atmos. Res., 94, 161-167, 2009.

Chen, J., Zhao, C. S., Ma, N., Liu, P. F., Göbel, T., Hallbauer, E., Deng, Z. Z., Ran, L., Xu, W. Y., Liang, Z., Liu, H. J., Yan, P., Zhou, X. J., and Wiedensohler, A.: A parameterization of low visibilities for hazy days in the North China Plain, Atmos. Chem. Phys., 12, 4935-4950, doi:10.5194/acp-12-4935-2012, 2012.

China Statistical Yearbook: 1995-2010, http://www.stats.gov.cn/ tjsj/ndsj/, access: 26 March 2014.

Danielson, J. J. and Gesch, D. B.: Global multi-resolution terrain elevation data 2010 (GMTED2010): US Geological Survey OpenFile Report, 26, 2011-1073, 2011.

Deng, J., Du, K., Wang, K., Yuan, C.-S., and Zhao, J.: Long-term atmospheric visibility trend in Southeast China, 1973-2010, Atmos. Environ., 59, 11-21, 2012.

Doyle, M. and Dorling, S.: Visibility trends in the UK 1950-1997, Atmos. Environ., 36, 3161-3172, 2002.

$\mathrm{Fu}, \mathrm{C}$. and Wu, J.: The Different Characteristics of Sunny Visibility over Southwest China in Recent 50 Years, Proc. Environ. Sci., Part A, 10, 247-254, 2011.

Liu, H. J., Zhao, C. S., Nekat, B., Ma, N., Wiedensohler, A., van Pinxteren, D., Spindler, G., Müller, K., and Herrmann, H.: Aerosol hygroscopicity derived from size-segregated chemical composition and its parameterization in the North China Plain, Atmos. Chem. Phys., 14, 2525-2539, doi:10.5194/acp-14-25252014, 2014.

Ma, N., Zhao, C. S., Nowak, A., Müller, T., Pfeifer, S., Cheng, Y. F., Deng, Z. Z., Liu, P. F., Xu, W. Y., Ran, L., Yan, P., Göbel, T., Hallbauer, E., Mildenberger, K., Henning, S., Yu, J., Chen, L. L., Zhou, X. J., Stratmann, F., and Wiedensohler, A.: Aerosol optical properties in the North China Plain during HaChi campaign: an in-situ optical closure study, Atmos. Chem. Phys., 11, 5959-5973, doi:10.5194/acp-11-5959-2011, 2011.

Molnár, A., Mészáros, E., Imre, K., and Rüll, A.: Trends in visibility over Hungary between 1996 and 2002, Atmos. Environ., 42, 2621-2629, 2008.

Ran, L., Zhao, C. S., Xu, W. Y., Lu, X. Q., Han, M., Lin, W. L., Yan, P., Xu, X. B., Deng, Z. Z., Ma, N., Liu, P. F., Yu, J., Liang, W. D., and Chen, L. L.: VOC reactivity and its effect on ozone production during the HaChi summer campaign, Atmos. Chem. Phys., 11, 4657-4667, doi:10.5194/acp-11-4657-2011, 2011.

Schichtel, B. A., Husar, R. B., Falke, S. R., and Wilson, W. E.: Haze trends over the United States, 1980-1995, Atmos. Environ., 35, 5205-5210, 2001.

Vautard, R., Yiou, P., and van Oldenborgh, G. J.: Decline of fog, mist and haze in Europe over the past 30 years, Nature Geosci., 2, 115-119, 2009.

Wu, J., Fu, C., Zhang, L., and Tang, J.: Trends of visibility on sunny days in China in the recent 50 years, Atmos. Environ., 55, 339-346, 2012.

Xu, W. Y., Zhao, C. S., Ran, L., Deng, Z. Z., Liu, P. F., Ma, N., Lin, W. L., Xu, X. B., Yan, P., He, X., Yu, J., Liang, W. D., and Chen, L. L.: Characteristics of pollutants and their correlation to meteorological conditions at a suburban site in the North China Plain, Atmos. Chem. Phys., 11, 4353-4369, doi:10.5194/acp-114353-2011, 2011.

Zhang, Q.: Residential energy consumption in China and its comparison with Japan, Canada, and USA, Energ. Build., 36, 1217-1225, h 2004.

Zhao, P., Zhang, X., Xu, X., and Zhao, X.: Long-term visibility trends and characteristics in the region of Beijing, Tianjin, and Hebei, China, Atmos. Res., 101, 711-718, 2011. 